\title{
REPRESENTAÇÕES SOCIAIS DE DIREITOS HUMANOS PRODUZIDAS POR ESTUDANTES DO ENSINO MÉDIO
}

\author{
Ricardo Gonçalves Vaz de Oliveira' \\ Caroline Rocha Pereira ${ }^{2}$
}

\section{Palavras-Chave}

representações sociais/ direitos humanos/ escolas/violações de direitos

\section{SUMÁRIO}

1. Introdução. 2. Referencial Teórico. 3. Participantes da Pesquisa e Coletas de Dados. 4. Forma de Análise dos Dados. 5. Caracterização do Local. 6. Resultados. 7.Discussão e Considerações Finais. 8. Referências.

\section{Resumo}

Este resumo tem por finalidade conferir abertura ao diálogo, à crítica, à tolerância, à compreensão e o respeito para com o outro, contribuindo, dessa forma, para a democratização e para a alteridade na escola, tendo em vista a cultura e a prática dos Direitos Humanos no campo educacional. Além disso pretende-se oportunizar a formação de sujeitos autônomos, conscientes dos seus direitos e deveres, preparados para o pleno exercício da cidadania. Nesse sentido, a ótica principal de análise da presente pesquisa é: como os estudantes do ensino médio representam os Direitos Humanos e como estão assimilando seus direitos e deveres, na vida e na escola? A presente investigação encontra-se referenciada no método de análise das representações sociais, sistematizado por Moscovici (2003), Jodelet (2001) e colaboradores, que se baseia na análise das práticas discursivas dos participantes, estudantes do ensino médio, de uma escola pública. As entrevistas foram gravadas, transcritas e sistematizadas por meio do procedimento de análise de conteúdo (BARDIN, 1979), obtendo-se assim, dez categorias temáticas que foram analisadas e discutidas. Portanto, tem-se a ratificação da problemática relacionada ao ensino de Direitos Humanos na Escola, cuja missão de elaborar estratégia e métodos capazes de conscientizar e gerar consequentes mudanças seja o desafio principal para os educadores e para os pesquisadores. 


\title{
SOCIAL REPRESENTATIONS OF HUMAN RIGHTS PRODUCED BY HIGH SCHOOL STUDENTS
}

\author{
Ricardo Gonçalves Vaz de Oliveira \\ Caroline Rocha Pereira
}

\section{Palavras-Chave}

social representations/ human rights/ school/ violations of rights

\section{Resumo}

With the culture and practice of Human Rights in the educational field, it is intended to open spaces for dialogue, criticism, tolerance, understanding and respect for the other, contributing to democratization and otherness in school. It also seeks to provide opportunities for the formation of autonomous subject, aware of their rights and duties, prepared for the full exercise of citizenship. In this sense, the fundamental question that guides this research is: how do high school students represent Human Rights and how are they assimilating their rights and duties in life and in school? The present research is based on the method of analysis of social representations, systematized by Moscovici (2003), Jodelet (2001) and collaborators, which is based on the analysis of participants' discursive practices, students of high school in a public school. The interviews were recorded, transcribed and systematized through the content analysis procedure (BARDIN, 1979), thus obtaining 10 thematic categories that were analyzed and discussed. In conclusion there is a problem related to the teaching of Human Rights in the School, which comes as a challenge for educators and researchers, whose mission is to develop strategies and methods capable of generating awareness and change of reality. 


\section{INTRODUÇÃO}

Conforme definição da Organização das Nações Unidas (ONU, 2018), os Direitos Humanos (DH) "são direitos inerentes a todos os seres humanos, independentemente de raça, sexo, nacionalidade, etnia, idioma, religião ou qualquer outra condição". Nessa perspectiva, incluem-se "o direito à vida e à liberdade, à liberdade de opinião e de expressão, o direito ao trabalho e à educação, entre muitos outros. Todos merecem estes direitos, sem discriminação".

Direitos Humanos são, segundo Henkin (1988), um termo de uso comum, mas não categoricamente definido cuja concepção se desdobra de forma a incluir reivindicações morais e políticas que, no consenso contemporâneo, todo ser humano tem ou deve ter perante sua sociedade ou governo, sendo tais aquelas reconhecidas como "de direito", e não apenas por amor, graça ou caridade.

As leis, objeto de estudo das Ciências Jurídicas, são criações humanas que evoluem a partir da necessidade de resolver determinadas situações. Nesse sentido, leis refletem valores e esses são conceitos psicológicos básicos, que podem ser definidos como padrões para a tomada de decisões e, consequentemente, para a própria quimera das leis.

Considerando os Direitos Humanos como um sistema de pensamento e parte de uma realidade social, a presente pesquisa tratou-os tanto como princípios avaliativos quanto representações sociais normativas, que permitem aos seres humanos organizar suas relações e interações, tendo como referência normativa a Declaração Universal dos Direitos Humanos (Doise, 2001).

As Representações Sociais (RS) referem-se a uma produção mental, dada por meio da construção ou da transformação de um objeto. Por meio destas representações, o objeto ou apresenta-se ou é substituído, torna-se presente e restaura-se simbolicamente, caracterizando o sujeito e a sua atividade, trazendo à tona a inserção social dos indivíduos como fonte de variação das representações (Doise, 2002).

Nesse sentido, por meio dos julgamentos de um grupo sobre os outros, as Representações Sociais foram criadas. Por conseguinte, o posicionamento do sujeito em relação ao meio social interferiria na forma como o indivíduo compreende a realidade. Então, percebe-se um tensionamento, conceituado como importante para a compreensão da sociedade, considerando as interações entre o nível psicológico e o nível sociológico como fenômenos de mão dupla. Assim, as formações sociais são construídas dinamicamente pelo conjunto de RS e ações dos indivíduos que as constituem (Doise, 1982).

Doise (1982) utilizou, ainda, o termo "representações sociais normativas" para designar as "ideias-força" em Direitos Humanos, caracterizando-as segundo um aspecto normativo, nem sempre explicitado, envolto em definições jurídico-institucionais. Logo, os DH seriam representações dessas "ideias-força", que podem orientar sobre os limites e as medidas das interações no grupo e entre os grupos, permitindo aos homens organizá-las. Nesse caso, a visão e a intencionalidade dos DH é universal, ao menos no nível de sua formulação. Tais ideias são, progressivamente, institucionalizadas e contidas nos princípios explícitos na Declaração Universal dos Direitos Humanos, que determina o respeito à integridade corporal do outro, sua liberdade e sua dignidade, além de seu acesso aos recursos necessários para viver dignamente e sua integração numa 
ordem social, assegurando proteção contra decisões arbitrárias (Doise, 2001).

Passini (2014) revelou que direitos e deveres são considerados, em uma perspectiva psicossocial, as bases da interação humana entre os indivíduos, de modo que nenhuma sociedade pode existir sem o estabelecimento de normas de comportamento. Uma pesquisa desenvolvida pelo referido autor a qual envolveu 134 adolescentes do ensino secundário de uma escola técnica da cidade de San Benedetto Del Tronto (Itália) - sugeriu que os alunos entrevistados possuíam noção de que os direitos eram importantes ferramentas de proteção de todos, porém, aqueles apresentaram dificuldades em limitar o exercício de seus próprios direitos em benefício de terceiros, ou seja, acreditavam que seus direitos eram superiores aos de outros indivíduos na mesma condição.

Outros dois estudos sobre representações sociais, realizados por Stellmacher, Sommer e Brahler (2005) em universidades alemãs com cerca de quatro mil estudantes - enfatizaram a importância da educação em DH, ao demonstrar que o nível de conhecimento dos indivíduos sobre o tema e documentos afins era bastante baixo, sendo que somente $1 \%$ daquela população pôde ser categorizada como 'militantes'.

Conforme indicado nas pesquisas supracitadas, a mera existência de normas e tratados internacionais - inclusive nos quais o Brasil é signatário - não foi suficiente para afastar, entre os indivíduos, a existência de concepções negativas a respeito de seus direitos e deveres. Apesar de formalmente os $\mathrm{DH}$ serem codificados e estruturados sob a forma de tratados, convenções e outros instrumentos do direito internacional, destacando-se, dentre esses, a Declaração Universal dos Direitos Humanos, de 1948 - as pessoas comuns constantemente adaptaram e recriaram seus próprios conceitos de $\mathrm{DH}$, inclusive com várias restrições e discrepâncias em relação a sua aplicação (Staerklé, Clémence, \& Spini, 2015).

Em pesquisa desenvolvida por Veiga (2001), em que 294 estudantes foram abrangidos de ambos os sexos e de diversas regiões de Portugal - identificou-se que tais alunos até reconheciam a existência de seus direitos, considerando-os fundamentais. Todavia, esta pesquisa constatou também que os estudantes habitantes de contextos escolares ou familiares adversos e desfavoráveis foram os mesmos a indicarem um menor grau de importância em relação aos seus direitos, sendo, inclusive, aqueles que menos perceberam a existência de tais direitos, nos ambientes escolar e residencial.

Para Maia (2014), é necessário desenvolver, durante a formação do aluno, uma consciência capaz tanto de tecer crítica quanto autocrítica, apoiada em saberes da filosofia, da história e das ciências sociais, embora se considerando a subjetividade como dialética entre o particular e o universal como concretizadora de uma singularidade.

Na tentativa de desvendar as características que cercam a moral, Piaget propôs que as características psicológicas do indivíduo passam por três fases de desenvolvimento, tal que cada uma sendo uma etapa de superação da anterior. Nesta teoria, a evolução de cada uma das fases se dá por meio da maturação biológica e por meio do contato com variadas experiências e vivências, por exemplo, as atividades desenvolvidas na escola (La Taille, 2014).

Contudo, como lembrado por Tavares (2007), antes de uma reflexão acerca das in- 
tervenções e estratégias educacionais capazes de impulsionar o aprendizado em DH, é primordial considerar localmente as representações que envolvem o tema, especialmente a existência, no imaginário social, de representações com conotações negativas, as quais distorcem o real significado de $\mathrm{DH}$.

Buscando articular os aspectos supramencionados, o presente estudo visa compreender as representações sociais dos $\mathrm{DH}$, segundo a perspectiva de discentes matriculados no ensino médio provenientes de escolas públicas paulistas de um município do interior com o intuito de mapear, por meio dos discursos dos sujeitos-alvo do estudo, reflexões relacionadas ao fenômeno investigado.

\section{REFERENCIAL TEÓRICO}

Diante do cenário apresentado, propôs-se a realização deste estudo com a finalidade de identificar, em uma perspectiva psicossociológica apoiada em orientação teórica e epistemológica, a TRS do autor romeno Serge Moscovici, na qual se sustenta o senso comum e o pensamento representativo como mediadores de novos conhecimentos e instrumentos geradores de ação nas relações sociais (Moscovici, 2003).

As representações sociais - fenômenos sempre ativos e agentes na vida social - são compostas por elementos informativos, cognitivos, ideológicos, normativos, crenças, valores, atitudes, opiniões, imagens etc., os quais são organizados em uma espécie de saber sobre o estado da realidade, sendo este o ponto no qual se estabelece a presente pesquisa científica, tendo como função a descrição, análise e explicação das dimensões, formas, processos e funcionamen- to dessas representações sociais (Jodelet, 2001).

Para Moscovici (2003), as representações sociais são estruturas psicológicas construídas a partir de símbolos compartilhados e enriquecidos por experiências empíricas, anteriormente vivenciadas pelos indivíduos, cujos conteúdos são produto de um longo processo que determina sua organização. Durante esse processo, isto é, durante essas experiências, novas informações e símbolos são transmitidos e recebidos durante a prática cotidiana de comunicação derivada de estruturas informais. A função das representações sociais, então, seria inovar agregando essas novas informações à estrutura de conhecimentos já existentes e dotados de certa estabilidade - por meio de mecanismos denominados como ancoragem e objetivação - construindo as representações sociais, com a finalidade de recriar objetos, ideias e seres desconhecidos, tornando-os mais próximos, familiares, compreensíveis e atuais.

Para Jodelet (2001), durante a análise do material coletado, os dados de um indivíduo isolado não são levados em consideração, mas as respostas individuais enquanto manifestações de tendências do grupo ao qual pertence. No entendimento da autora, o conteúdo a ser estudado refere-se a situação social definida, possuindo uma história pessoal e social.

\section{PARTICIPANTES DA PESQUISA E COLE- TA DE DADOS}

Os participantes do estudo são discentes do terceiro ano do ensino médio e foram convidados a participar das entrevistas, após contato em momentos de interação pública em que o pesquisador foi a campo. Ao todo, a 
instituição possuía, no ano de 2017, quatro turmas de alunos formandos, 3 (três) no período da manhã e um no noturno, sendo a totalidade destes de 127 indivíduos (informação fornecida pela Diretoria de Ensino de Sertãozinho/SP em consulta realizada no ano de 2017).

Já no segundo semestre do ano de 2016, foram realizadas três entrevistas e, no primeiro semestre do ano seguinte, mais 5 entrevistas, sendo interrompida a coleta por ter sido verificado que os dados contidos nas entrevistas atingiram a saturação, ou seja, quando se constatou que os dados coletados, seja pela sua robustez ou repetição, são o suficiente para subsidiar a teorização almejada, não necessitando de novos elementos para nela se aprofundar (Minayo, 2018).

A coleta de dados foi obtida por meio de entrevistas semiestruturadas realizadas no local de estudo do entrevistado. Segundo Turato (2008), a entrevista semiestruturada é indicada nesse contexto, pois permite maior troca de experiência entre entrevistador e entrevistado.

As questões norteadoras das entrevistas buscaram investigar as representações sociais sobre Direitos Humanos concebidas pelos integrantes supracitados, ou seja, os sujeitos do estudo, da mesma forma que a compreensão de como essas representações afetam ou influenciam nas relações sociais cotidianas dos indivíduos entrevistados.

Já as entrevistas foram realizadas em ambiente reservado, na sala dos professores, em horário em que o estudante não estava participando de nenhuma atividade acadêmica, de modo a permitir o sigilo da entrevista e não prejudicar suas atividades escolares. A coleta de dados somente foi iniciada após a assinatura do respectivo Termo de Consentimento Livre e Esclarecido, no caso de participantes maiores de idade, ou do
Termo de Consentimento pelos responsáveis legais e do Termo de Assentimento (pelos participantes), em caso de adolescentes.

A pesquisa teve seus dados analisados segundo a abordagem qualitativa. Conforme Minayo (2014, p. 22), pesquisas qualitativas podem ser entendidas ". . . como aquelas capazes de incorporar a questão do significado e da intencionalidade como inerentes aos atos, às relações e às estruturas sociais, . . . como construções humanas significativas".

\section{FORMA DE ANÁLISE DOS DADOS}

Para melhor análise e compreensão das informações colhidas, as entrevistas foram transcritas e os dados obtidos classificados e organizados por categorias fazendo uso da técnica de Análise de Conteúdo (Bardin, 1979).

A análise por categorias é o tipo mais antigo e utilizado em pesquisas; na análise temática, as categorias são construídas conforme os temas emergem do texto. Para se classificar as informações em categorias é necessário identificar o que elas têm em comum, permitindo assim seu agrupamento. Nesse sentido, de acordo com Moscovici (2003, p. 63), "categorizar alguém ou alguma coisa significa escolher um dos paradigmas estocados em nossa memória e estabelecer uma relação positiva ou negativa com ele".

\section{CARACTERIZAÇÃO DO LOCAL}

O estudo foi desenvolvido em uma escola estadual subordinada hierarquicamente à Diretoria de Ensino da Região de Sertãozinho/SP, ambas localizadas no município de Sertãozinho/SP, cidade localizada na região nordeste do estado de São Paulo, cuja popu- 
lação era - tendo como referência o ano de 2016 - de 121.412 (cento e vinte e um mil quatrocentos e doze) habitantes (IBGE, 2017).

Foram encaminhados pedidos de informações, por meio do Serviço de Informações ao Cidadão do Governo do Estado de São Paulo, protocolos n 742161612326 e n 686661710891 , no qual se verificou no ano de 2017, a instituição onde se realizou a pesquisa possuía 588 alunos matriculados. Ao todo, a escola possuía em 2017, quarenta professores e quatro turmas de $3^{\circ}$ ano do ensino médio, sendo três no período matutino e uma no período noturno. Juntos, todos os matriculados no $3^{\circ}$ ano do ensino médio, somam 127 indivíduos, população de onde advieram os participantes do presente estudo.

\section{RESULTADOS}

As entrevistas tiveram um tempo médio de cinquenta minutos de duração, realizadas de acordo com o roteiro de entrevista. Após a conclusão da transcrição, iniciaram-se suas análises por meio de uma leitura minuciosa dos discursos. Após a extração de unidades de significado das principais enunciações, os dados obtidos foram interpretados e relacionados ao referencial teórico utilizado no presente estudo, formaram-se dez categorias temáticas, conforme segue:

\subsection{Envolvimento e práticas em Direitos Humanos no contexto escolar}

As marcas discursivas que formam esta categoria referem-se ao envolvimento dos entrevistados com práticas ou atividades que consideram se tratar de temas relativos aos Direitos Humanos. O que se pode observar é a quase inexistência de comunicação, no cotidiano dos alunos, sobre questões relacionadas a valores humanos, direitos ou obrigações, sendo as poucas interações que admitiram ter realizado, ocorreram dentro da escola, no momento do desenvolvimento de trabalhos, como parte de conteúdo ministrado em disciplinas, pelos professores.

Destaca-se também que nas marcas discursivas dos alunos não foram identificadas a vivência em outras atividades (fora do contexto escolar), envolvendo a temática de Direitos Humanos, que possam estar relacionadas a EDH. Seguem os recortes que constituem esta categoria:

S1: "em sociologia a gente chegou na parte que tinha uma tabela pra gente completar perguntando dos direitos civis... direitos sociais e direitos humanos".

S2: "era em sala de aula falavam sobre aborto e racismo só passava a matéria falava sobre isso um pouquinho e parava".

S3: "Na minha aula de sociologia esse ano a professora tem discutido bastante sobre isso [direitos humanos], sobre agressão física, abusos dentro de prisão, sobre como que os detentos funcionam lá dentro entendeu? Se sofrem abuso ou não. São essas partes que ela conversa com a gente".

S5: "professor de filosofia também fala sobre, sobre isso aí . . . tipo assim, "nois" separa quem é, quem é a favor e quem não é".

S6: "quando eu ia na igreja, eles falavam muito desses direitos".

S6: "só em aula mesmo [conversou sobre Direitos Humanos]". 
S6: "a gente até fez um trabalho dos direitos e deveres".

S7: "não converso, mas eles botam em prática o que deveria ser feito".

S7: "não sou meio interativo com base nisso".

S7: "não me envolvi muito".

S7: "debatia um pouco e mandavam a gente pesquisar".

S8: "só dentro da sala, com a professora junto, aí nós discutimos sobre isso".

\subsection{Consciência de direitos e deveres}

Os sujeitos da pesquisa reconhecem que são indivíduos dotados de direitos, deveres e obrigações impostos não só a si, mas a coletividade, o que muito se aproxima da função exercida pela "cidadania". Nesta categoria foram inseridas marcas discursivas que refletem as representações de direitos que são protegidos ou garantidos pelos Direitos Humanos. Inclusive, há a ideia de que os direitos essenciais deveriam ser de acesso a todas as pessoas.

S1: "você tem o direito de frequentar uma escola, mas você também tem o dever se querer uma boa educação... de cobrar uma boa educação... você ter o direito de poder é expressar sua opinião mas você tem o dever de compreender a o outro e de respeitar... então ela é meio que isso... que nem você tem o direito de votar e o dever de participar da política também".

S2: "todos deveriam ter direito a educação, saúde, trabalho".

S3: "Mas as pessoas mereciam ter no mínimo onde comer ou morar"
S4: "deveria ter mais... mais lugar para as "criança" "brincar", mano, isso é direitos humanos também".

S6: "têm o dever de respeitar o próximo como um igual, respeitar as leis, tipo leis de transito, não cometer crimes".

S6: "cidadania, os direitos de voto, direitos de educação, de saúde, essas coisas, eu acho que é Direitos Humanos".

S7: "educação, deixa eu ver, saneamento básico, ... direito de ter seu título de eleitor".

S7: "pagar imposto é um dever da pessoa, ir lá e se alistar na Junta Militar ... dever de ir para a escola".

S8: "educação é um direito de todos".

S8: "eu tenho que trabalhar".

S8: "todos os seus direitos têm os seus deveres".

S8: "você está trabalhando em uma firma, você tem o direito e você tem também os deveres de ir na firma".

S8: "você tem um dever de vir na escola".

\subsection{Responsabilidade pela aplicação dos} Direitos Humanos

A categoria é formada por marcas discursivas que indicam de quem, no imaginário dos estudantes, é a responsabilidade de promoção e defesa dos Direitos Humanos. Extraiu-se do material analisado, a compreensão de que a responsabilidade de lutar pela aplicação e proteção não seria isoladamente apenas Estatal ou do individual, mas de ambos. Contudo, caberia ainda ao "povo" 
a responsabilidade de fiscalizar e cobrar do Estado a efetivação de tais direitos.

S1: "não tem eu acho que é de cada um... tipo... todo mundo sabendo os seus direitos eu acho que eles sabem que eles têm que respeitar... têm que impor".

S3: "Um morador de rua, ele não tem onde morar, ele não tem nenhum tipo de benefício. Seria alguma coisa que eles poderiam estar fazendo. Gerar algum tipo de serviço pequeno, por exemplo. É um cara ir ali todo dia pintar um muro... varrer uma calçada e ganhar algum dinheiro por isso. Seria uma ajuda. Não tem. Se ele não tiver um estudo... um currículo ou uma carteira ele não vai ter essa chance. Então cada um tem que ajudar no que pode".

S4: "Tem o governo. Porém, eu acho que governo não ajuda, tem pessoas que lutam pra isso mas também não adianta você lutar por alguma coisa que ninguém acredita. Aí essa obrigação fica com todos".

S5: "A população é a responsável, porque, tipo assim, o governo não vai ver isso aí, ele não vai se preocupar. Agora, se a população correr atrás disso, o governo vai prestar atenção e ele vai fazer as coisas".

S6: "o povo tem responsabilidade de cobrar dos governantes".

S7: "é mais das pessoas, porque, por parte de Estado, o Estado foi imposto pelo povo".

S7: "seria o brasileiro, o povo brasileiro, mas o povo brasileiro deixa muito a desejar".

6.4 Violações de Direitos Humanos vivenciadas ou reconhecidas
Esta categoria reúne marcas discursivas na qual os entrevistados manifestam se já vivenciaram ou não alguma situação em que consideram ter ocorrido alguma violação aos $\mathrm{DH}$ ou direitos da pessoa.

Os discursos dos participantes apresentam contradições, pois os entrevistados não se enxergam como potenciais vítimas de violações de direitos, contudo, em outro momento, ao longo do discurso, narram ter vivenciado situações que, em tese, caracterizam-se pela ausência de direitos. Assim, aparenta que os participantes não se enxergam no contexto de vítimas ou testemunhas de situações envolvendo violações de direitos básicos.

É possível auferir que, para os entrevistados, as representações de "violações de direitos" estão relacionadas a situações em que ocorrerem abusos e injustiças 'realmente graves' e não 'meramente' a ausência de algum "direito fundamental".

S1: "comigo nunca aconteceu nenhum tipo de violação de direitos. Também nunca presenciei nada disso, acho".

S1: "Sempre houve aqueles casos né [de violência na escola]... que nem... eu sei que ano passado roubaram a bicicleta do meu amigo na escola. Porque lá entra no portão e tem o pátio com o local pra amarrar a bicicleta. E no intervalo alguém/teve dois casos... no intervalo alguém foi e jogou a bicicleta em cima do telhado... de um aluno... e no outro caso roubaram uma bicicleta e eu não sei do que que virou esse caso eu sei que meu amigo conseguiu outra bicicleta... acho que pegou a da irmã... não sei... mas não 
sei se foi feito algo a respeito pela escola".

S1: "de preconceito por homofobia já teve dentro da escola, teve um caso de tipo a pessoa ser gay levar uma cadeirada".

S3: "Injustiça, você fala? Não. Injustiça nunca presenciei na escola nem violação de direito".

S3: "A minha [escola] ano passado era muito violenta. Já teve tiro na porta, de borracha e tal. Era muito violenta sim. Hoje é um lugar onde é bem tranquilo. Ano passado e esse ano se teve algum tipo de briga foi cinco no máximo".

S4: "Acho que nunca vi uma situação dessa [de desrespeito ou injustiça]"

S4: "Uma amiga minha, o namorado dela bateu nela na frente da escola e a gente viu ela andando na rua, a gente passou por ela, ela tava chorando perguntou o que tava acontecendo e ela não quis falar. Depois ela ligou pra gente pediu pra gente ir na casa dela".

S5: "Eu já vi professora, inclusive que era diretora, que tem preconceito com negro".

S5: "acredito que sempre sou respeitado em meus direitos".

S5: "Não, nunca aconteceu comigo não".

S6: "não que eu me lembre [de ter algum direito violado]".

S6: "peguei muitos professores que não estavam nem aí com os alunos".

S7: "vejo crianças na rua, jogado, não estuda, não faz nada, fica o dia inteiro na rua ... saneamento básico . . não tem como isso, é coisas jogadas na rua".

S7: "nunca fui desrespeitado nessa parte de Direitos Humanos".

S7: "vi muito com amigos, com colega, eu vi muito [violações de direitos]".

S7: "vou para prender bandido, eu vou para impor, para impor isso com minhas próprias mãos".

S8: "passei uma vez só [situação de desrespeito a direitos] . . . numa outra [empresa] que eu trabalhava".

S8: "só queria que eu fizesse aquilo, mas ele era também um empregado, aí onde deu treta e acabou me mandando embora".

\subsection{Mediação e justiça restaurativa no} contexto escolar

A violência é vivenciada no cotidiano dos alunos no próprio contexto escolar. No discurso discente, além de denunciar a existência, demonstra-se também a descrença em relação as tentativas da instituição de ensino na tentativa de contenção ou diminuição dentro do ambiente educacional. Projetos que buscam desenvolver valores de justiça restaurativa, como é o caso do professor mediador são considerados ineficientes, sendo tratados meramente como procedimentos burocráticos para os quais os alunos envolvidos em algum tipo de infração disciplinar são encaminhados.

S1: "eu já vi ela chamando os alunos do fundamental na sala dela pra conversar e tudo mais... mas da minha sala eu nunca vi ninguém indo lá falar com ela que eu saiba ou ela chamando alguém".

S2: "eles [a direção da escola] tentavam 
[fazer algo para diminuir a violência] na medida do possível, mas não resolvia muita coisa não resolvia quase nada".

S4: "A reunião [com a professora mediadora] não mudou nada. Continuei a mesma coisa. Ela só conversou comigo pra eu não continuar fazendo aquilo porque tipo... foi muito assim e eu não era de fazer essas coisas. Eu era super calma e ela queria saber o motivo que me levou a fazer aquilo. Mas depois/eu fiquei duas semana só. Depois passou eu nunca mais fui".

S4: "todo mundo que brigava ia falar com ela [a professora mediadora] só para não levar suspensão e essas coisas".

S5: "a minha mãe foi lá, na escola, "nois" conversou, ela falou para eu pedir desculpa para a mulher, a mediadora falou, e eu falei que não vou, eu falei que eu "tô" certo. Falei: "como a mulher quer cobrar de mim uniforme, sendo que eu que ....".

S5: "pra mim eu acho que não [funciona] esse negócio pra mediadora. Mas essa parte, tipo assim, a mediadora eu acho que é mais pra essa parte de aconteceu alguma briga ela vai falar com os pais".

\subsection{Respeito aos Direitos Humanos}

Esta categoria contempla a perspectiva dos entrevistados no que se refere ao cumprimento dos/respeito aos Direitos Humanos. Os sujeitos compreendem que os direitos das pessoas não são respeitados, como regra, ou dentro de algum contexto. Observa-se ainda a existência de sentimento de conformidade dos entrevistados em acreditar que desrespeito às leis, aos direitos e aos abusos tratam-se de algo comum.

S1: "hoje em dia ninguém respeita ninguém, acho que os Direitos Humanos não são muito não, eu acho assim".

S3: "Na minha os Direitos Humanos não são respeitados".

S4: "Acho que nenhum tipo de direito importante hoje é respeitado. Só tá lá, mas não tá respeitado".

S6: "em países mais pobres, tipo a África, não tem como as crianças terem educação, então por um lado eles não respeitam os Direitos Humanos".

S6: "na escola eu acho que sim, eu acho que é [respeitado]".

57: "pedaços de papel imposto para as pessoas ver que tem uma lei".

S7: "só penso em uma lei jogada de lado".

S7: "leis são impostas, mas nunca são cumpridas, muitas delas não são praticadas".

S8: "o próprio empregado, o próprio patrão, o encarregado, tudo abusa, não tem jeito".

S8: "são poucas pessoas que respeitam".

S8: "você sempre vai explorar seu ajudante, quanto mais você explorar seu ajudante, você vai ficar de boa".

\subsection{Professor, o promotor dos Direitos} Humanos

Esta categoria reúne marcas discursivas que traduzem a compreensão do aluno a respeito do papel desenvolvido pelo profes- 
sor, visto como um agente cuja missão seja transmitir aos alunos os conhecimentos relativos aos direitos e obrigações. É válido esclarecer que a maioria das marcas discursivas foram respostas da pergunta elaborada pelo entrevistador, qual seja: "na sua visão, qual seria o papel da escola na proteção dos Direitos Humanos?".

O que se percebe, seguindo a lógica identificada nas representações dos entrevistados, é que o docente, por meio do ato de ensinar, é visto como um promotor dos Direitos Humanos no ambiente escolar. Assim, na visão dos alunos, para que haja uma maior promoção de tais direitos, deve-se investir mais na figura do professor, seja cobrando maior desempenho em suas atividades, seja por meio de sua valorização.

S1: "ela [professora] refez o grêmio... aí chamou eu... chamou uns outros amigos meus e aí a gente começou a montar um projeto pra fazer".

S1: "conversando sobre isso ele [o professor] tá tanto nos ensinando como explicando também... dando exemplos e se tem algum caso assim que acontece às vezes por alguma explicação dele ou por algum exemplo que ele dá acaba servindo de exemplo pra pessoa e ela consegue tomar alguma decisão... fazer alguma coisa a respeito. Então o professor é quem vejo que consegue sim ajudar os alunos com esses assuntos assim... com esses temas... conversando e tratando na sala de aula ele consegue ajudar, eu acho".

S2: "Poderia ter mais palestras na escola né... poderia ter mais conversa sobre isso, tipo passar alguns vídeos, tentar entrar mais nesse assunto".
S5: "escola como um todo deveria de ouvir o aluno, dele participar das aulas e discutir isso na sala".

S6: "para a escola se envolver um pouco, é cobrar um pouco mais dos professores para que eles façam o serviço mesmo".

S6: "professores são muito preocupados em que a gente aprenda mesmo ... acho que eles estão um pouco envolvidos nisso".

S6: "o problema está no governo, eles meio que acabam com os professores, contradizem eles".

S7: "Eles [os professores] passam a informação para sobre isso, sobre as leis também".

S8: "colocar mais professores para falar de direitos e deveres, Direitos Humanos, essas coisas".

\section{8 papel dos estudantes}

As marcas discursivas desta categoria contemplam o papel que os alunos teriam na proteção e promoção dos Direitos Humanos na perspectiva dos entrevistados.

Com base na análise das entrevistas realizadas, percebe-se que, na visão dos alunos, a busca de direitos, por parte dos estudantes, poderá ocorrer através da construção de conhecimentos a respeito da problemática junto ao ambiente escolar e com o auxílio do professor.

Novamente se destaca a ausência de citação de outras ferramentas democráticas de busca por direitos, como associações de estudantes, grêmios estudantis e a política. 
S1: "os alunos poderiam buscar mais direitos tendo bastante conversas com professor sobre essas coisas".

S2: "eles têm que procurar estudar mais sobre isso aprendendo e estudando sobre o assunto".

S3: "eu sinto isso. Que o governo e a escola não conversa com a gente. Porque eles simplesmente mandam as coisas. Não têm noção do que tá acontecendo na escola".

S5: "a gente deveria cobrar mais a escola para ser democrática. Só aula, só aula não 'vira'. Igual, tem professor lá que leva, sei lá, que leva para dar filme sobre o conteúdo do assunto".

S6: "[os estudantes] poderiam buscar mais, saber sobre o assunto, que a gente escuta falar em jornal".

S6: "[os estudantes] deveriam se informar um pouco mais, pesquisar, perguntar para os professores".

S7: "correr atrás e saber dos seus próprios direitos".

S7: "atrás de pesquisa, livros, perguntando informações para os professores, essas coisas".

S8: "discutir com os professores sobre esses direitos, deveres".

\subsection{Direitos Humanos é coisa de bandido}

Existe entre os participantes um sentimento de que a legislação brasileira é branda no sentido de ser muito permissiva, o que acaba contribuindo para a situação de vio- lência do país. Assim, os criminosos e até adolescentes infratores, conscientes dessas "brechas", estariam se aproveitando da situação para praticarem atos criminosos com a certeza de impunidade. Entre os próprios entrevistados, jovens e adolescentes, há um discurso tendente a tornar mais rígidas as leis que cuidam das medias socioeducativas e da persecução criminal.

S1: "Minha opinião [sobre os adolescentes infratores] acho que isso é questão de necessidade mudar a lei, tem muitos que é por causa de frescura que quer entrar pra ver como que é e fica nessa e se arrepende depois."

S2: "hoje em dia o jovem de quinze, quatorze anos, que quer trabalhar e não pode tem que trabalhar só depois dos dezesseis anos tipo não é certo ainda e essa questão eu acho que devia diminuir sim porque geralmente essas pessoas que faz, que assalta, rouba, já faz pensando que não vai dá nada que não vai acontecer nada com eles. Só depois que fizer dezoito ano".

S3: "se um 'de menor' vem e dá tiro em um cidadão, aí ele vai pegar três anos preso e depois cumprir e fazer serviço beneficente aí. Não. Pra mim isso não é certo. Ele tem que pagar pelo que o outro tá pagando também. Ele tirou uma vida. Aquela pessoa não vai mais viver. Então é o certo ele pagar por isso sim. Os direitos humanos tinha que proteger o cidadão também".

S3: "o massacre do Carandiru aquela vez. Passou na mídia e tal. E os direitos humanos se revoltou por causa disso".

S4: "Eu discuti isso na escola, tipo, eu acho 
que tem que diminuir pra 14 nem pra 16 porque eu acho que hoje em dia tá cada vez menor aí. Ah porque eu sou menor aí eu posso. Então eu acho que tem que diminuir mesmo. Eles aproveitam da lei".

S4: "Eu sinto. Eu vejo isso. Todo mundo fala. Ah você vê um menor sendo preso na TV ele mesmo fala 'eu vou sair'... é porque ele sabe que vai sair... não vai ficar... é vai preso dois meses na casa/como é que é FEBEM né?".

S4: "não acredito em justiça porque hoje em dia tem fianças. Você comete o seu crime você paga uma fiança e sai. Se tivesse justiça não existia fiança".

S4: "lembro que também discutimos sobre o massacre do Carandiru né. Os policiais mataram eles [os presos], só que eles tavam pagando porque eles [os presos] quiseram... e os policiais não tinham o direito de tirar a vida deles né, mas eles [os presos] também não tinha que fazer rebelião. Eu acho que isso assim é o que tem mais na cabeça de todo mundo sobre os direitos humanos".

S5: "quando eu ouço sobre Direitos Humanos, acabo me lembrando da escola, das discussões sobre os presidiários. Lembro da escola (risos)".

\subsection{Representações Sociais sobre Direitos Humanos}

As marcas discursivas surgiram nos discursos dos participantes após serem indagados sobre "o que vêm em sua mente quando ouve falar em Direitos Humanos?". Verificar-se que as unidades de significados extraídas convergem em compreender os Direitos Humanos em algum tipo de código de condutas, sendo que a ausência significaria a existência de violações da ordem social. Apesar da visão deturpada sobre aqueles, que foge de seu conceito científico, sua objetificação é considerada como positiva dada sua importância.

S1: "Direitos Humanos ele meio que engloba um pouco os outros direitos como civis e políticos e é mais aquela questão de ter meio que o básico né... direitos humanos".

S2: "não sei explicar o que é essa questão de Direitos Humanos mas deve ser algo assim pra proteger os nossos direitos né".

S3: "o que eu entendo é que os Direitos Humanos ele tem o dever de proteger a integridade. É o principal foco dele. Eu acho que de certa forma é muito correto porque o que tá acontecendo lá dentro a gente não vê. Só que acho que eles deveriam ficar só na integridade".

S3: "então os Direitos Humanos é só uma parte disso. É como se fosse uma terceirizada do governo".

S5: "quando eu ouço sobre Direitos Humanos, acabo me lembrando da escola, das discussões sobre os presidiários".

S6: "pesquisadores poderiam fazer o que eles quisessem com pessoas".

S6: "Direitos Humanos, é o que traz nossa cidadania".

S6: "se não tivesse, o mundo iria ser uma anarquia total".

S7: "policial, nem sabe o do porquê a pes- 
soa cometeu o crime, repreende a pessoa, não sabem nem o porquê, se está certo ou está errado".

S7: "moral e ética, tem muito a ver, na verdade os dois estão muito conectados".

S8: "para você cobrar uma coisa, você tem que ficar ciente que mais para frente, o que você cobrar de uma pessoa pode ser cobrado para você".

S8: "se você fazendo uma coisa certa, você vai ter os seus direitos, é a mesma coisa, eu vou discutir, desrespeitar e você vai me respeitar?".

\section{DISCUSSÃO E CONSIDERAÇÕES FINAIS}

Os dados coletados na observação em campo e os levantamentos realizados junto à Diretoria de Ensino de Sertãozinho permitem concluir que, teoricamente, a unidade educacional - onde ocorreu a pesquisa - destaca-se pela previsão de atividades e de ensino envolvendo Direitos Humanos e, nesse sentindo, contribuindo com a construção e transmissão de valores de cidadania e dignidade.

Considerando a boa vontade, nos aspectos formal e normativo da instituição, a criação ou sequer a busca de uma cultura em Direitos Humanos, no contexto escolar, não foi identificada na prática e na vivência, entre os alunos participantes ou entre os demais agentes sociais, educando e educadores, que contribuíram para uma melhor compreensão do fenômeno aqui estudado.

É válido destacar a suma importância da convivência durante o período de estudo junto ao ambiente escolar (observação de campo), fator este que permitiu compreen- der mais a sensação de insatisfação e inconformismo existente junto aos educadores (professores e outros servidores públicos). Tal sentimento, em síntese, presente nos discursos de boa parte dos educadores, foca no sentimento de revolta dos profissionais (servidores públicos), no âmbito do órgão empregador, o governo estadual, através de queixas frequentes, como falta de reposição salarial há mais de quatro anos e a existência de uma sensação de abandono e de impotência.

Para os educadores, a falta de estrutura permite que a educação funcione apenas em nível precário, ou seja, o aluno sai da escola, sendo ensinado (talvez não aprendido), o mínimo necessário para que possa desempenhar atividades do mercado de trabalho ou a realização de processos seletivos, como concursos ou vestibulares. Assim, não haveria espaço ou estrutura necessária para realização de atividades de construção de saberes e ideias envolvendo as ideias de valores de cidadania e ética que forjam a teoria dos DH, cuja previsão (de ser trabalhada no contexto escolar) é formal.

Nesse sentido, conforme destaca Lapo e Bueno (2002), no jogo pedagógico, o insucesso de estratégias administrativas é sempre atribuído ao professor que, ao tentar se livrar da "culpa" normalmente a devolve para o Estado, a esvanece facilmente através de mecanismos diversos. No final do jogo, parece ficar para o docente a sensação nada agradável de incompetência ou de fracasso". Para o autor:

O professor está na base desse sistema, e deve, por isto, responder às expectativas dos coordenadores, diretores, supervisores, além de outros superiores. Precisa, também, responder às expectativas dos alunos 
e dos pais desses alunos. Entretanto, essas expectativas nem sempre são coerentes e passíveis de conciliação. O professor consegue realizar ou chegar a um equilíbrio entre essas expectativas? Como assumir posturas diferentes, condizentes com a realidade e com as suas próprias expectativas, num sistema regulamentado e dirigido? (Lapo \& Bueno, 2002, p.247)

Instala-se dessa forma uma tensão entre dever e crença. Surge um problema de difícil resolução: como poderiam os educadores terem como obrigação funcional a concepção de criação de ideais sobre a filosofia e valores dos Direitos Humanos se não acreditam que a EDH no ambiente educacional funciona? Ou por meio do raciocínio crítico e científico-dedutivo (universo reificado) ou por meio comunicação e interação das RS presentes no imaginário popular (universo conceitual), a transmissão de valores da filosofia dos direitos em tela nesta discussão exige a crença do agente social, crer que aquilo é importante e crer que tal filosofia é um ideal a ser alcançado.

Essa situação ainda é reforçada pelo pensamento de responsabilidade que o professor carrega. Junto a categoria "professor, o promotor dos Direitos Humanos", o docente é compreendido como um tipo de agente que tem a missão que transmitir aos alunos os conhecimentos relativos aos direitos e obrigações, sendo o próprio ato de ensinar visto como meio de promoção dos DH. Tendo os alunos desta forma a visão de que, para que haja uma maior promoção de tais direitos, deve-se investir mais na figura do professor, seja cobrado maior desempenho em suas atividades ou por meio de sua valorização.

Esse pensamento induz o discente ter sobre o professor o sentimento de cobrança, que muitas vezes pode ir além de sua responsabilidade, como também demonstra a concepção da ideia do centralismo educacional clássico, de mera transferência de conhecimento e não de construção do saber, como é esperado que ocorra na educação contemporânea. Essa ideia sobre o papel que o docente assume e sua importância para o aluno, ficou bem desenhada em uma pesquisa desenvolvida por Cândido (2014), a qual relevou que, para os alunos que participaram de seu estudo, a representação social do "bom professor" consistia no profissional engajado no futuro do aluno e que saiba transmitir o conteúdo, pois, os próprios discentes ansiavam por algo que deveria ser transferido.

A categoria "o papel dos estudantes", complementa bem essa situação. Observou-se que para os estudantes, a única contribuição possível para a promoção dos $\mathrm{DH}$ seria através dos estudos, cumprindo as obrigações escolares, acabando por reafirmar essa posição de centralismo na figura do professor e de imaginário continuísta da transmissão do conhecimento. Pela lógica dos participantes, a promoção dos direitos humanos poderia ser alcançada por meio da figura do docente e na busca individual do estudante junto a unidade escola (estudando), não sendo indicada nenhuma situação em que essa situação pudesse vir de atividades desenvolvidas por iniciativa própria dos alunos, sem dependência institucional.

Ao centralizar no professor o papel de promoção dos direitos básicos, a escola, enquanto órgão administrativo e político, pode acabar eximindo-se de sua responsabilidade, pois ocasionais cobranças dos alunos, enquanto cidadãos e usuários de serviços públicos, poderão ser insuficientes para que hajam eventuais mudanças administrativas. 
Inclusive, permite uma injusta responsabilização do docente, em caso de insucesso da instituição na formação ética e moral do aluno, o que, na prática, exige um esforço e complexidade que dificilmente seria superado apenas com o empenho do professor.

Isso não significa, contudo, que o docente não exerça na EDH um posicionamento estratégico ímpar. Sem dúvidas, a fim de que aquela seja efetiva, se faz necessário estudar e buscar novas formas e estratégias que realmente conduzam o profissional da educação a acreditar nos programas que visam a construção dos valores trazidos pela filosofia dos Direitos Humanos. Partindo desta premissa, o ambiente escolar trata-se de local para realização de práticas que almejam a construção do sujeito. Ao professor, portanto, caberia o protagonismo da criação e da execução de estratégias pedagógicas que permitam o crescimento individual do aluno, embora seja sabido de que esse não é o único responsável.

O Plano Nacional de Educação em Direitos Humanos (Brasil, 2007) define não somente que a educação em DH deva ir além da mera aprendizagem cognitiva, mas também decorrer de práticas envolvendo a escola e a comunidade local, pois, na sociedade contemporânea, a escola é a localização da estruturação de concepções de mundo, de consciência social, de promoção de valores, da diversidade social e cultural e da formação para a cidadania e dos sujeitos sociais.

Nesse aspecto, duas categorias de análise dos discursos dos alunos denunciam o que já foi apontado pelos educadores durante a observação de campo. Tais categorias são "envolvimento e práticas em direitos humanos no contexto escolar" e a "mediação e justiça restaurativa no contexto escolar".
Assim, verifica-se pela concepção dos alunos (categoria envolvimento e práticas em Direitos Humanos no contexto escolar) e pela observação em campo que a temática em si é basicamente trabalhada (ou reconhecida) apenas em sala de aula, não sendo identificado pelos participantes nenhuma atividade educacional que possa estar relacionada com essa construção de saberes e valores.

Ainda por esse ângulo, os resultados indicam que a principal fonte de informações dos estudantes sobre o direitos e obrigações provêm da própria escola, através de poucos exercícios que foram realizados em sala de aula ou na forma de conteúdo de disciplinas. Poucos alunos discutiram temas relacionados aos Direitos Humanos (na concepção do entrevistado), fora do contexto escolar (como na igreja, por exemplo). Essa revelação evidencia novamente o papel da educação no contexto de promoção dos $\mathrm{DH}$. No tocante às atividades do professor mediador, presente em diversas escolas objetivando o desenvolvimento de valores da justiça restaurativa, estas foram percebidas pelos alunos como mero instrumento burocrático pelo qual são submetidos quando se envolvem em episódios de indisciplina . Desta forma, não aparenta haver para os alunos, compreensão da importância da implementação do Programa Sistema de Proteção Escolar do Governo do Estado de São Paulo.

Em consonância, a categoria "respeito aos Direitos Humanos", traz a visão dos participantes que não acreditam na lei e no sistema de justiça. A legislação é frágil e falha, na concepção do sujeito 7, trata-se de "pedaço de papel imposto para as pessoas verem que tem uma lei" e que "leis são impostas, 
mas nunca são cumpridas, muitas delas não são praticadas".

Existe um problema crônico no Brasil de reconhecimento das instituições de justiça e de aplicação do direito. $\mathrm{O}$ acesso ao sistema de justiça, em situação de igualdade trata-se do pilar do sistema democrático e dos Direitos Humanos. Este é o modo pelo qual o jurisdicionado pode reclamar ao Estado e solicitar intervenção frente a uma situação de violação de direitos. Esta prerrogativa foi democraticamente conquistada pelos cidadãos, sob a forma de "o mais básico dos Direitos Humanos", conforme explica Spengler e Spengler Neto (2011). O Estado falha em efetivar o direito aos cidadãos, no cumprimento do direito com justiça, na participação social e assim, ao construir inspiração para o exercício e respeito aos direitos e da própria cidadania, abre espaço para a insatisfação e decepção sentida pelos indivíduos, o que desestrutura e desgasta a credibilidade de que o nosso sistema ainda dispõe.

Percebe-se também que os sujeitos do estudo compreendem que situações de abusos e de violações a direitos são comuns; acreditam na existência de direitos universais aos quais todos deveriam ter acesso, porém acabam se conformando com o desrespeito dentro da dinâmica social. Essa mesma descrença ao sistema de justiça e ao direito nos remete a categoria "direitos humanos é coisa de bandido", na qual se aparenta que os estudantes, embora reconheçam a importância dessa filosofia em outras categorias, ancoram suas compreensões na crença que os Direitos Humanos são frequentemente utilizados para a proteção de criminosos e outros infratores da lei. Para os participantes, os "bandidos" tem conhecimento das brechas que existem em nossa legislação (frouxa e permissiva) e se aproveitam dessa situação para a prática de outros delitos.

As filosofias dos Direitos Humanos encontram-se em constante evolução e, em razão disso, não são unanimidade em todo mundo. Existem também aqueles que possuem uma visão equivocada sobre o assunto, entendendo que os defensores dos Direitos Humanos estão preocupados apenas em "defender bandidos". Fato este que ratifica a importância da compreensão social sobre, pois a ideia, há tempos, partiu da premissa de que todos os humanos são iguais por naturezas, tendo, desta forma, direitos iguais (Silva, 2009).

Os resultados encontrados se assemelham ao apontado na pesquisa elaborada por Queiroz (2001). Nesta, as entrevistadas, mães de estudantes, referiram-se aos Direitos Humanos como sendo "algo para atrapalhar a educação dos filhos e para defender bandidos". Entre outros destaques, a pesquisa de Queiroz conclui que "em todas as questões, as classes referentes a uma visão negativa e mais restrita dos DH estão relacionadas a mães de classe socioeconômica baixa e de baixo nível de escolaridade" e uma "visão positiva e mais ampla dos direitos provém de mães de classe média e de nível de escolaridade superior".

Já em uma pesquisa desenvolvida por Santos (2009), com a finalidade de compreender as representações de servidores de uma instituição ressocializadora, percebeu-se que as origens do conhecimento em direitos provem principalmente da escola e da mídia, sendo a última responsável por boa parte das representações deturpadas sobre o assunto. $O$ resultado em questão se assemelhou a pesquisa acima informada, em que se identificou uma concepção negativa.

A explicação de Queiroz (2001) para justifi- 
car essa diferença consiste "as mães de classe média têm um acesso mais amplo aos direitos de modo geral", enquanto as mães de classe baixa, sobretudo em função da deficiência do governo no provimento dos direitos, "vivenciam muitas situações em que se veem sem direitos ou em que esses direitos são violados".

Uma pesquisa, elaborada no ano de 2016, envolvendo a análise das RS nos discursos de deputados federais (Oliveira et al, 2017), identificou que a ideia popular de descrença na justiça criminal é um dos elementos propulsores das tentativas de reformas visando o enrijecimento da lei criminal, principalmente do Estatuto da Criança e Adolescente. Essa ideia especialmente daqueles que acreditam, inclusive, na leg islação como responsável pela situação de violência que vitima a população brasileira. Assim, para os parlamentares, o anseio pelo fim das impunidades trazidas pelas ideias de direitos humanos é um desejo do "povo" que deve ser respeitado, por meio da mudança do ordenamento jurídico.

O desejo de punir os responsáveis pela prática de um delito, é algo comum em qualquer sociedade. Contudo, destaca-se o mesmo arcabouço jurídico de direitos fundamentais que assegura a punição de um infrator, dentro do sistema de justiça pela prática de um crime, também reconhece que o mesmo é sujeito de direito. Esse reconhecimento, de que todos possuem os direitos básicos, comumente pode ser alcançado por meio de uma educação pautada na promoção destes direitos. A EDH representa uma importante ferramenta reflexiva e de transformação da realidade, ainda que focada no aprendizado fora do contexto escolar.

Já na categoria "consciência de direitos e deveres", os participantes da pesquisa reconheceram que são indivíduos dotados de direitos, deveres e obrigações impostos não só a si, mas a toda coletividade, o que muito se aproxima do papel exercido pela "cidadania". Nesta categoria, inseriram-se marcas discursivas que refletem as representações de direitos protegidos ou garantidos pelos Direitos Humanos.

Os entrevistados demonstram consciência de que também possuem obrigações, cumprindo as normas sociais impostas pela coletividade, bem como aquelas advindas de lei (alistamento militar, pagar impostos, etc.). Nesse sentido, a escola também reafirma um importante papel de fomentar atividades e práticas sociais destinadas a discussão de obrigações e direitos.

Outro ponto válido citar são os exemplos de Direitos Humanos que foram lembrados pelos alunos, dentre eles, o direito a educação. Tal resultado não é por acaso, pois, conforme percebe-se uma pesquisa sobre representações sociais de estudantes do ensino médio conduzida por Franco e Novaes (2001), a escola e a educação são os caminhos nos quais os jovens depositam a esperança para conseguir melhor situação financeira, em decorrente, por exemplo, de melhores empregos.

A categoria "violações de DH vivenciadas ou reconhecidas" demonstrou que os participantes possuem aparente dificuldade de se enxergar como potenciais vítimas de violações de direitos. As marcas discursivas com afirmações contraditórias por parte dos alunos revelam certa dificuldade sobre o reconhecimento acerca do que presenciaram ou foram vítimas, em linhas gerais, podem ser classificadas como violações de direitos. Inclusive, os entrevistados possuem 
conhecimento de que certas atitudes se tratam de violação de um direito, mas não tem a consciência de que estarem vivenciando tal realidade.

Ultrapassando a esfera política, a educação também tem o papel de desenvolvimento e conscientização. A palavra conscientização foi criada, segundo Paulo Freire, por uma equipe de professores do Instituto Superior de Estudos Brasileiro, em 1964, mas foi Helder Câmara quem se encarregou de difundi-la e traduzi-la para o inglês e francês (Freire, 1980). Nessa perspectiva, o indivíduo tem percepção de sua realidade e de sua existência. Esta conscientização não ocorre de forma separada, ou seja, o ser humano toma consciência de si no mundo, pois nem sempre a realidade é apresentada de forma clara, sendo muitas vezes o que conhecemos ser interpretado de forma falsa ou errônea (Freire, 1980).

Nesta lógica, "conscientizar significa ultrapassar a esfera espontânea de apreensão da realidade, até avançar a uma esfera crítica na qual a realidade se dá como objeto cognoscível e no qual o homem assume uma posição epistemológica" (Freire, 1980, p.26). "A conscientização não se dá fora da prática. É através da conscientização que transformamos a realidade. É a inserção crítica na história. Implica que os homens assumam o papel de sujeitos que fazem e refletem o mundo" (Freire, 1980, p.26). A conscientização implica em ser capaz de emitir um juízo crítico sobre a realidade ou conhecimento produzido.

Feitosa (2009), em sua pesquisa sobre as concepções de Direitos Humanos, concluiu que o aumento da compreensão sobre, não se trata somente pelo acúmulo do conhecimento com o passar do tempo. Para o pesquisador, a complexidade acerca das representações sobre DH evoluem conforme os indivíduos vivenciam o que Piaget denominou como conflito sócio cognitivo, o qual trata-se do processo de desenvolvimento cognitivo e moral do indivíduo por meio do conflito de valores transmitidos pelos sujeitos sociais durante as interações do cotidiano.

Assim, admite-se que a forma como os estudantes refletem acerca do tema DH pode ser influenciada pela maneira como enxergam tais direitos em relação a suas próprias vidas e como são apresentados a eles, especialmente no contexto escolar; No entanto, espera-se que as representações - acerca dos direitos - que estes jovens possuem, possam ir se alterando na medida em que são convidados a trabalhar, refletir e a raciocinar no que tange à aplicação de tais direitos e deveres em seu próprio contexto social.

As diferenças das percepções sobre Direitos Humanos entre os estudos podem estar na explicação de Doise (2003) sobre o tema, o qual teoriza as representações criadas pelo grupo sobre DH também relacionam-se às violações que os indivíduos já estiveram inseridos. Em suas palavras, o autor explica que "é exatamente as violações dos direitos que acabam, muitas vezes, tornando as pessoas conscientes de que esses direitos devem ser aplicados, o que as tornam parte social da realidade". Nesse seguimento, grupos que já foram vítimas da criminalidade urbana estão mais propensos a conceber DH como sendo "coisa de bandido"; visão esta também constatada no presente estudo e discutido acima.

Conforme destaca Camino et al (2004), a visão do governo em não se empenhar na proteção dos Direitos Humanos é algo co- 
mum entre os cidadãos dos países da América Latina. Em pesquisa conduzida pela referida autora com a finalidade de compreender as representações que universitários possuem sobre o envolvimento do governo com os $\mathrm{DH}$, chegou-se ao resultado que o governo brasileiro é visto como "não-defensor dos Direitos Humanos".

No cenário apresentado pelo presente estudo, na categoria "responsabilidade pela aplicação dos Direitos Humanos", existe a compreensão de que a responsabilidade de lutar pela aplicação e proteção dos DH não seria isoladamente apenas do Estado ou do indivíduo, mas de ambos. Contudo, caberia ainda ao "povo" a responsabilidade de fiscalizar e cobrar do Estado a efetivação de tais direitos.

Por fim, a categoria "representações sociais de Direitos Humanos", traz uma visão de que os alunos possuem certa dificuldade em conceituar o significado ou ideia dos DH. É possível verificar ainda que as unidades de significados extraídas convergem em compreender os $\mathrm{DH}$ em algum tipo código de conduta, sendo que sua ausência, significaria a existência de violações a ordem social; Apesar da visão deturpada sobre os DH, que foge de seu conceito cientifico, sua objetificação é em algo considerado como positivo e com importância. Pelos discursos, é possível identificar a ideia de valores éticos e morais que deverão ser adotados durante a escolha de algum tipo de conduta a ser adotada (certa ou errada), durante a busca de um "bem maior", como no caso da busca por "cidadania" ou "justiça".

Destarte, a associação de ideias identificadas nos resultados na compreensão de Direitos Humanos, revela a visão de uma espécie de código de conduta, baseado na ética e moral, cuja finalidade é a busca de cidadania e da justiça, para evitar a prática de abusos. Esse entendimento sincroniza-se com a teorização realizada por Doise (2003), o qual descreve o universo consensual construído em torno dos $\mathrm{DH}$ como sendo representações sociais normativas, caracterizadas como normas sociais e princípios contratuais de comportamentos coletivos, que se encontram implícitos nas relações do cotidiano que Ihes originam.

Sendo assim, interpreta-se que as visões trazidas pelos participantes estão baseadas em valores e símbolos extraídos do contexto social. Isto é, não meramente a compreensão que DH são "direitos previstos em algum tipo de norma legal", se afastando de sua conceituação científica, o que demonstra, de certa forma, a existência de um imaginário coletivo sobre o assunto.

É possível concluir que há uma problemática relacionada a questão, sendo um desafio para educadores e para pesquisadores cuja missão consiste em elaborar estratégias e métodos de EDH capazes de gerar conscientização e mudança de realidade. Para isso, necessário far-se-á que realizem-se de maneira aprofundada maiores estudos e pesquisas, a fim de que se explore e trace o caminho para a eficácia do ensino aqui abordado.

\section{REFERÊNCIAS}

Bardin, L. (1979). Análise de conteúdo. Lisboa: Edições 70. Camino, C., Camino, L., Pereira, C., \& Paz, M. (2004). Moral, direitos humanos e participação social. Estudos de Psicologia, 9(1), 25-34.

Cândido, C. M., de Assis, M. R., \& Ferreira, N. T. (2014). A representação social do "bom professor" no ensino superior. Psicologia \& Sociedade, 26(2), 11.

Doise, W. (1982). L'explication en psychologie sociale. Paris: Presses Universitaires de France. 
Doise, W. (2001). Droits de l'homme et force des idées. Paris: Presses universitaires de France.

Doise, W. (2002). Da psicologia social à psicologia societal. Psicologia: teoria e pesquisa, 18(1), 27-35.

Doise, W. (2003b). Human rights as social representations. New York: Routledge.

Henkin, L. (1988). The rights of man today. New York: Columbia University Press.

Jodelet, D. (2001). Representações sociais: Um domínio em expansão. In D. Jodelet (Org.), As representações sociais (pp. 17-44). Rio de Janeiro, RJ: Ed. UERJ. La Taille, Y. (2014) Moral e ética: dimensões intelectuais e afetivas. Porto Alegre: Artmed Editora.

Lapo, F. R. \& Bueno, B. O. (2002). O abandono do magistério: Vínculos e rupturas com o trabalho docente. Psicologia USP, 13(2), 243-276.

Maia, A. F. (2014). Psicologia, política e direitos humanos: ambiguidades e contradições. Revista Interdisciplinar de Direitos Humanos, 131-144.

Minayo, M. C. (2017). Amostragem e saturação em pesquisa qualitativa: consensos e controvérsias. Revista Pesquisa Qualitativa, 5(7), 01-12.

Minayo, M. C. S (2014). O desafio do conhecimento: Pesquisa qualitativa em saúde (14a ed.). São Paulo: Hucitec.

Moscovici, S. (2003). Representações sociais: investigações em psicologia social. São Paulo, SP: Vozes.

Organização das Nações Unidas. (2018). O que são os direitos humanos?. A ONU e os Direitos Humanos. Recuperado de http://www.dudh.org.br/definicao/.

Passini, S. (2014). Adolescents' Commonsense Understanding of Rights and Duties The Effect of the Individualization of Rights on a Rights Dilemma. Youth \& Society, 46(4), 460-477.

Plano Nacional de Educação em Direitos Humanos. (2007). Brasília, DF: Ministério da Educação, Ministério da Justiça, UNESCO. Recuperado de http://portal.mec. gov.br/index.php?option=com_docman\&view=download\&alias=2191-plano-nacional-pdf\&category_slug=dezembro-2009-pdf\&Itemid=30192.

Staerklé, C., Clémence, A., \& Spini, D. (2015). A social psychology of human rights rooted in asymmetric intergroup relations. Peace and Conflict: Journal of Peace Psychology, 21(1), 133.

Stellmacher, J., Sommer, G., \& Brähler, E. (2005). The Cognitive Representation of Human Rights: Knowledge, Importance, and Commitment. Peace and Conflict: Journal of Peace Psychology, 11(3), 267-292.

Tavares, C. (2007). Educar em direitos humanos, o de- safio da formação dos educadores numa perspectiva interdisciplinar. In Educação em direitos humanos: fundamentos teórico-metodológicos (pp. 487-503). João Pessoa, PB: Ed. da UFPB.

Turato, E. R. Tratado da metodologia da pesquisa clínico-qualitativa: construção teórico-epistemológica, discussão comparada e aplicação nas áreas da saúde e humanas (3a ed.). Petrópolis, RJ: Vozes, 2008. Veiga, F. H. (2001). Students' perceptions of their rights in Portugal. School Psychology International, 22(2), 174-189.

Data de submissão: 19/06/2018

Data de aceite: 23/10/2018 